\title{
Symposium in Honor of Irving I. Gottesman (December 29, 1930-June 29, 2016)
}

\author{
Nancy L. Segal \\ Psychology Department, California State University, Fullerton, CA, USA
}

\begin{abstract}
The June 2016 death of our esteemed colleague, Dr Irving I. Gottesman, was felt as an extreme loss at so many levels by colleagues, students, friends, and family across the globe. Irv's stellar contributions to the field of twin research will continue to be remembered and cited for many years to come. In commemoration of his life and work, I organized a symposium at the 16th meeting of the International Society for Twin Studies, held in Madrid, Spain, November 16-18, 2017. The panelists included mostly former students, as well as colleagues, who presented their scientific research and personal remarks reflecting Irv's profound influence in shaping their lives and careers. A chronology of Irv's academic positions and honors is included in the introduction to this special issue of Twin Research and Human Genetics, followed by brief sketches of the panel participants; their scholarly papers and personal reflections follow.
\end{abstract}

Keywords: Irving I. Gottesman, symposium, twin research, psychiatric genetics, personality

There was no better venue than the 2017 International Twin Congress to recognize the contributions of Dr Irving Isadore Gottesman to twin research, as well as his lasting influence on countless colleagues and students. Many people could have been members of the symposium organized in his honor because Irv's influence was far reaching. The international conferences, memorials, and tributes that followed Irv's untimely loss reflect that fact. Irv is pictured below, outside his office at the University of Minnesota, in Elliott Hall.

Irving Gottesman enjoyed a stellar career. At the time of his death in 2016, he was a Senior Fellow in the Department of Psychology at the University of Minnesota and a Visiting Professor at the Institute of Psychiatry at King's College, London. However, he held many prominent positions throughout his career, beginning in the early 1960s; they are listed below beginning with the most recent:

2001-2016: Senior Fellow in Psychology, University of Minnesota

2001-2012: Bernstein Professorship in Adult Psychiatry (Endowed Scholar: University of Minnesota Regents)

2001-2016: Adjunct Professor of Psychiatry, University of Minnesota

2001-2016: Sherrell J. Aston Professor of Psychology Emeritus, University of Virginia

2000-2001: Shannon Center for Advanced Studies, University of Virginia

1985-2001: Sherrell J. Aston Professor (1994-2001),

Commonwealth Professor of Psychology (1985-1993),
Department of Psychology; Professor of Clinical Pediatrics (Medical Genetics), University of Virginia, Charlottesville

1987-1988: Fellow, Center for Advanced Study in the Behavioral Sciences, Stanford, California

1980-1985: Professor of Psychiatric Genetics, Washington University School of Medicine St. Louis, Departments of Psychiatry, and Genetics and Cell Biology

1966-1980: Associate Professor to Professor (1968), Departments of Psychology, Psychiatry, and Genetics and Cell Biology; Director of the Behavioral Genetics Center, University of Minnesota

1979: (6 months) Visiting Professor, Department of Psychiatry, Washington University School of Medicine, St. Louis

1972-1973: Guggenheim Fellow at Psykologisk Institut, Kommunehospitalet, Copenhagen and Visiting Professor, University of Copenhagen

\section{RECEIVED 10 April 2018; ACCEPTED 20 April 2018}

ADDRESS FOR CORRESPONDENCE: Nancy L. Segal, Department of Psychology, California State University, Fullerton, CA 92834, USA. E-mail: nsegal@fullerton.edu

My guest editorship of this special issue of Twin Research and Human Genetics was generously supported by a 2018 Summer Stipend, awarded to me by the College of Humanities and Social Sciences, at California State University, Fullerton. I wish to extend many thanks and warm wishes to the panel participants, their colleagues, and the Gottesman family. 


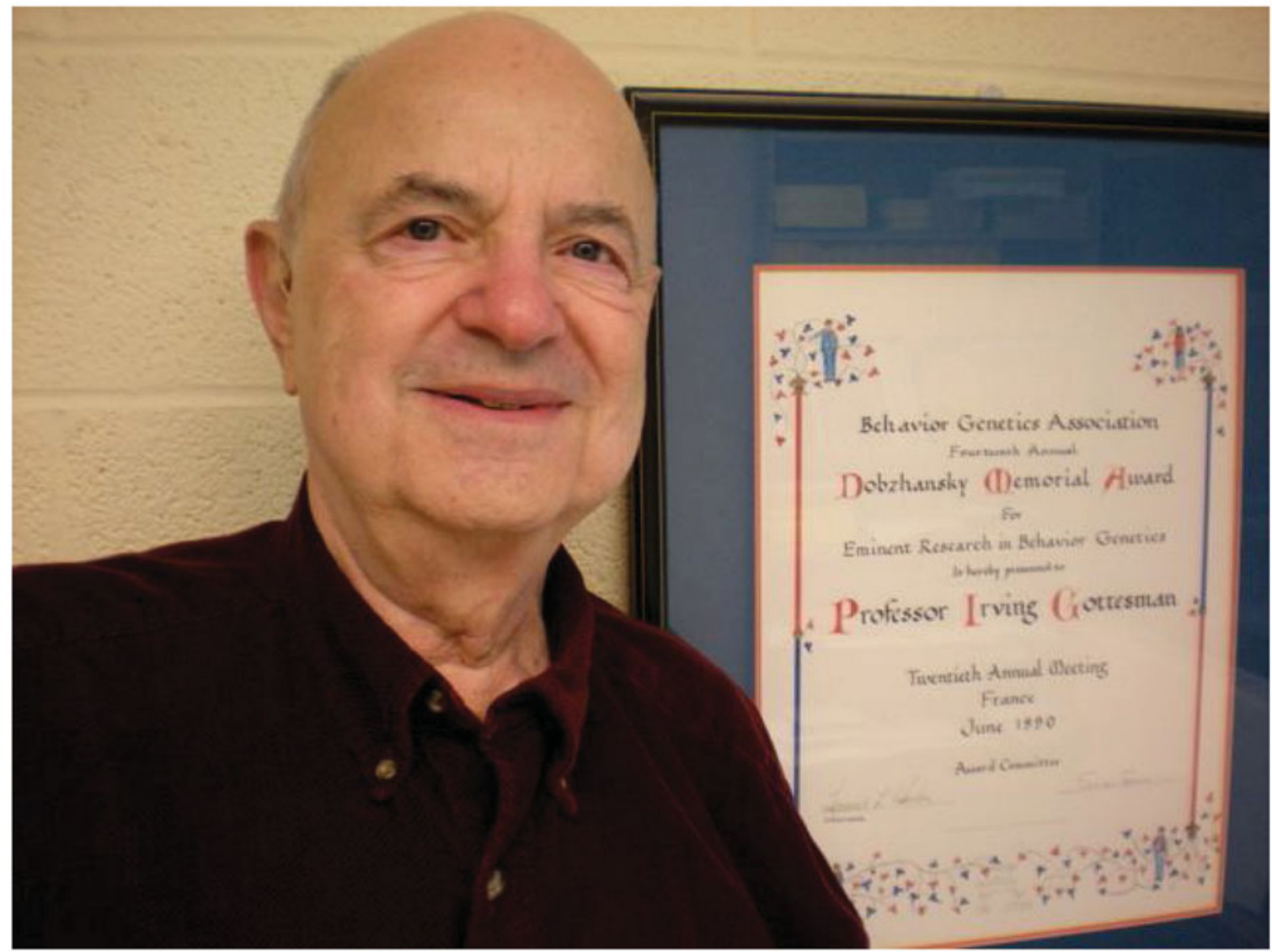

\section{FIGURE 1.}

(Colour online) Dr Irving I. Gottesman standing outside his office in the Department of Psychology, Elliott Hall, at the University of Minnesota, October, 2009. Note the prestigious Dobzhansky Award certificate on his door, given to him in June 1990. I took this photo while researching my book Born Together-Reared Apart: The Landmark Minnesota Twin Study (Segal, 2012). Photo credit: Nancy L. Segal.

1963-1966: Clinical Assistant Professor to Associate Professor of Psychology, Department of Psychiatry, University of North Carolina Medical School and Psychology Department

1963-1964: NIMH/USPHS Special Fellow in Psychiatric Genetics, University of London, Institute of Psychiatry, Maudsley-Bethlem Hospital; Medical Research Council Psychiatric Genetics Unit (Eliot Slater, Director).

1960-1963: Lecturer in Psychology, Departments of Social Relations and Psychology, Harvard University 1959-1960: Clinical Psychology Resident, U.S. Veterans Hospital, Department of Psychiatry, Minneapolis, Minnesota

1957-1959: USPHS Fellow, Clinical Psychology, A. H. Wilder Child Guidance Clinic, St. Paul, Minnesota 1956-1957: Teaching and Research Assistant, Department of Psychology, University of Minnesota

Irv Gottesman published well over 250 scientific papers, nearly 100 book chapters, and 19 books and monographs over the course of his career. He also authored 25 comprehensive book reviews and 12 brief ones. Everyone has their favorites among Irv's publications, and I am no exception: I have most admired (and cited) his 1989 paper, co-authored with Aksel Bertelsen of Denmark who was also a contributor to this symposium. Their paper, titled 'Confirming Unexpressed Genotypes for Schizophrenia: Risks in the Offspring of Fischer's Danish Identical and Fraternal Discordant Twins', capitalized on the unique relationships generated when monozygotic (MZ) twins marry and have children, formally known as the twin-family design (Gottesman \& Bertelsen, 1989). In these families, the twin aunts and uncles become 'genetic mothers' and 'genetic fathers' to their nieces and nephews who, in turn, become their 'genetic children'. In addition, the two sets of children, while legal first cousins, are equivalent to half-siblings. In contrast, when DZ twins marry, the parent-child, aunt-niece, uncle-nephew, and cousin-cousin relationships that evolve are typical of ordinary families because fraternal twins share half their genes, on average, just like full siblings. Gottesman and Bertelsen (1989) noted that, in 1971, Margit Fischer found that the risk of schizophrenia among the children of discordant MZ twins was the same, while only 
the children born to the affected members of discordant DZ twins were affected. They concluded that unaffected MZ twins can transmit unexpressed disease susceptibilities to their children, speculating that the unaffected parents' lack of symptoms might reflect the absence of environmental stressors or other triggers that might activate their predisposition.

Gottesman was the recipient of over 50 prestigious medals and honors, among them the Distinguished Scientist Award (Society for a Science of Clinical Psychology, American Psychological Association, 1994); the Gold Medal for Life Achievement in the Science of Psychology (American Psychological Foundation, 2007); and the Grawemeyer Award in Psychology (University of Louisville, 2013). He was also a licensed clinical psychologist and a Diplomate in both clinical psychology and assessment psychology.

In 2001, I conducted an interview with Dr. Gottesman that was published in this journal, then under the title Twin Research (Segal, 2001). At that time, more than one festschrift had taken place in recognition of his retirement at age 71 years, so I posed this question to him: How should we think of you on the occasion of your retirement? In his usual modest and joking manner, Gottesman conceded that he had no idea that early in his career he was starting an 'avalanche of twin studies'. He then went on to discuss his seminal twin-based books, papers, and projects that focus on personality and psychopathology, tying these topics to the study of epigenetics.

Aside from leaving an extensive body of groundbreaking academic research, Irv is also famous for the collegiality and support he unfailingly showed toward researchers everywhere, and to the members of the symposium panel, most of whom were his former students. (Irv directed the doctoral dissertations of 36 advanced graduate students and supervised the research of 7 postdoctoral fellows.) Together, the panelists and I addressed the question: How shall we think of Dr Irving I. Gottesman in terms of his lifelong contributions to twins and twin studies? In our series of symposium papers, we variously describe our associations with Irv, his influence on our work, and our current research that bears his indelible imprint. Some contributors included their students and colleagues as co-authors, exemplary of Gottesman's scholarly collaboration and support.

\section{Presenters}

1. Dr Lisbeth DiLalla, School of Medicine, Department of Psychology, Southern Illinois University. Her twin research examines how genes and environment correlate and interact to affect young children's social development. Dr Gottesman was her thesis advisor, as well as a friend and colleague.

2. Dr David DiLalla, School of Medicine, Department of Psychology, Southern Illinois University. His twin re- search explores genetic and environmental influences on psychopathology and personality. Dr Gottesman was his thesis advisor, as well as a friend and colleague.

3. Dr Sheri Berenbaum, Department of Psychology, Pennsylvania State University. Her interests concern hormonal influences on gender development. Dr Gottesman was her postdoctoral advisor in behavioral genetics at the University of Minnesota, as well as her mentor, colleague, collaborator, and friend.

4. Dr Nancy L. Segal, Department of Psychology, State University, Fullerton. Her twin research lies at the juncture of developmental psychology, behavioral genetics, and evolutionary psychology. She directs the Twin Studies Center on the campus, a facility she founded in 1991. Dr Gottesman was her friend and colleague.

5. Dr Eric Turkheimer, Hugh Scott Hamilton Professor of Psychology, University of Virginia. He conducts theoretical and empirical research targeted toward understanding the relationship between the genotype and complex human behavior. Dr. Gottesman hired him as an Assistant Professor at the University of Virginia in 1986, and served as his mentor for the next 30 years.

6. Dr Danielle Dick, Departments of Psychology, African American Studies, and Human and Molecular Genetics, Virginia Commonwealth University. Her research focuses on how genetic and environmental influences affect the development of patterns of substance use, childhood conduct problems and depression. Dr Gottesman was her undergraduate mentor, as well as a friend a colleague.

\section{Discussants}

1. Kaare Christensen, University of Southern Denmark and Duke University. He is Director of the Danish Twin Registry and conducts interdisciplinary aging studies that combine methods from epidemiology, genetics, and demography. He was a long-time colleague of Dr Gottesman, both in Denmark and in the United States.

2. Aksel Bertelsen, Translational Neuropsychiatry Unit, Department of Clinical Medicine, University of Aarhus. He collaborated with Dr. Gottesman for many years on psychiatric genetic studies of schizophrenia that involved twins and families. Bertelsen and Gottesman were longtime friends and colleagues. He could not be present at the symposium due to health reasons, but wished to contribute to this special issue.

A number of colleagues had to decline the invitation to contribute to, or attend, this symposium because of health issues, travel concerns, and/or previous obligations. It is, however, imperative to mention the late Dr James (Jerry) Shields at the Institute of Psychiatry in London, with whom Irv collaborated for many years on twin studies of schizophrenia. Shields authored the second major study of twins raised apart (Shields, 1962), a topic that was of great 
interest to Gottesman, and one with which he would become closely involved when he returned to the University of Minnesota. Gottesman and Shields later co-wrote their classic 1972 work, Schizophrenia and Genetics: A Twin Study Vantage Point (Gottesman \& Shields, 1972), turning 'Gottesman and Shields' into a familiar phrase among psychiatric genetic researchers (Segal, 2001). Shields's untimely death in 1978, at age 60 from a heart attack, was a tragic loss for his family and friends, and for the entire community of twin researchers. In a touching tribute to his friend, published in Behavior Genetics, Gottesman wrote that 'behavior genetics and twin research lost a well-renowned scholar and gentle man-for-all-seasons' (Gottesman, 1979, p. 1). Gottesman went on to establish the James Shields Award for Lifetime Contributions to Twin Research, an honor given to a deserving individual at each Twin Congress. Irv occasionally lamented to me that if Jerry had been alive today, their collaborative studies would have proceeded with amazing speed because of the quick communication made possible by the internet.

\section{References}

Gottesman, II. (1979). In memoriam: James Shields (19181977). Behavior Genetics, 9, 1-6.

Gottesman, I. I., \& Bertelsen, A. (1989). Confirming unexpressed genotypes for schizophrenia: Risks in the offspring of Fischer's Danish identical and fraternal discordant twins. Archives of General Psychiatry, 46, 867-872.

Gottesman, I. I., \& Shields, J. (1972). Schizophrenia and genetics: A twin study vantage point. New York, NY: Academic Press.

Segal, N. L. (2001). Reflections: An interview with Professor Irving I. Gottesman on the occasion of his festschrift. Twin Research, 4, 275-277.

Segal, N. L. (2012). Born together - Reared apart: The landmark Minnesota twin study. Cambridge, MA: Harvard University Press.

Segal, N. L. (2001). Twin classics: Research that always inspires. Twin Research and Human Genetics, 18, 478-484.

Shields, J. (1962). Monozygotic twins: Brought up apart and together. London, UK: Oxford University Press. 